\title{
A INDÚSTRIA DE LATICÍNIOS NO BRASIL - UM ESTUDO EXPLORATÓRIO
}

\author{
LUIZ PAULO DE LIMA* \\ RONALDO PEREZ \\ JOSÉ BENÍCIO PAES CHAVES
}

\begin{abstract}
A indústria de laticínios é de grande importância para o Brasil devido ao suprimento de produtos de alto valor nutricional e à geração de emprego e renda nos meios rural e urbano. Assim, este trabalho teve como objetivo caracterizar estabelecimentos de laticínios do Brasil, com registro no Serviço de Inspeção Federal (SIF), quanto a aspectos produtivos, gerenciais e mercadológicos. De um universo de 1.188 laticínios com SIF, foi feito contato com 377 gestores destes estabelecimentos e enviados questionários para 292 deles, entre novembro de 2014 e janeiro de 2015, obtendo-se um total de 68 respostas. A partir dos questionários respondidos, foi realizada uma análise exploratória, calculando-se estatísticas descritivas das frequências observadas das variáveis, procedendo-se teste de médias e teste de associação, quando aplicável. Verificou-se que a amostra é representativa da população de estabelecimentos de laticínios no que diz respeito à distribuição regional do Brasil. Os estabelecimentos respondentes são, basicamente, micro e pequenas empresas, com baixa capacidade de processamento. Observou-se que a ociosidade é um problema com grande presença junto aos micro e pequenos estabelecimentos, fruto da operação reduzida e da dificuldade de aquisição de leite. Observouse também que estes estabelecimentos estão direcionados ao atendimento de mercados regionais e nacional, com principalmente queijos frescos e de média maturação. Verificou-se que os gestores têm experiência prévia tanto na função quanto no setor, sendo esta última, aparentemente, mais valorizada pelas empresas. As principais dificuldades apontadas pelos gestores estão relacionadas à concorrência desleal, oscilações de mercado e à falta de mão de obra qualificada.
\end{abstract}

PALAVRAS-CHAVE: PORTE; PRODUTOS LÁCTEOS; LEITE; ALIMENTOS; FÁBRICA.

*Mestre em Ciência e Tecnologia de Alimentos. Universidade Federal de Viçosa/UFV - Instituto de Ciências Exatas e Tecnológicas - 35690-000 - Florestal - MG - Brasil - luiz.paulo@ufv.br

**Doutor em Engenharia de Alimentos. Universidade Federal de Viçosa/UFV - Departamento de Tecnologia de Alimentos - Viçosa - MG - Brasil - rperez@ufv.br

${ }^{* * *}$ Ph.D. em Food Science. Universidade Federal de Viçosa/UFV - Departamento de Tecnologia de Alimentos - Viçosa - MG - Brasil - jbchaves@ufv.br 


\section{INTRODUÇÃO}

Em 2013, a produção de leite in natura do Brasil atingiu a marca de 34,3 milhões de toneladas, o que fez do País o quarto maior produtor mundial (FAO, 2016). Em 2015, a produção de leite in natura esteve entre as seis mais importantes atividades agropecuárias do País, representando $5,8 \%$ do valor bruto da produção agropecuária brasileira (MAPA, 2016).

Entre as regiões brasileiras, considerando dados de 2014, a produção de leite in natura esteve concentrada principalmente nas regiões Sul $(34,7 \%)$ e Sudeste $(34,6 \%)$, seguidas pelas regiões Centro-Oeste (14,1\%), Nordeste (11,1\%) e Norte (5,5\%) (IBGE, 2016a).

Mais do que um dos maiores produtores mundiais (FAO, 2016), a importância do setor lácteo brasileiro passa também pelo grande número de estabelecimentos existentes, pelo número de empregos gerados e pela agregação de valor e, consequentemente, geração de renda. De acordo com dados do Ministério do Trabalho e Emprego (MTE, 2015), existiam no Brasil, em 2013, 6.381 indústrias de laticínios, as quais foram responsáveis pelo estabelecimento de mais de 100 mil empregos formais. Em 2014, o setor de laticínios obteve um faturamento líquido de 55,2 bilhões de reais, atingindo o terceiro lugar no ranking de faturamento das indústrias de alimentos (ABIA, 2016).

O que se sabe é que o setor da indústria brasileira de laticínios é marcado pela concentração de um grande número de empresas de micro e pequeno porte, com algumas empresas de grande porte (Ferreira et al., 2008; Brunozi Júnior et al., 2012). Este perfil pode ser reforçado pelo registro de mais de 6.000 indústrias de laticínios no País (MTE, 2015), em 2014, os 13 maiores concentraram $38,1 \%$ de toda a captação formal de leite cru (Milkpoint, 2015). Contudo, apesar do conhecimento acerca do cenário descrito, tornam-se necessárias caracterizações mais profundas e detalhadas que permitam informar profissionais, direcionar políticas públicas e a cooperação do setor com instituições de pesquisa e extensão. Desta forma, este estudo propõe realizar uma caracterização de estabelecimentos de laticínios do Brasil em relação a aspectos de produção, mercado e gerenciamento.

\section{MATERIAL E MÉTODOS}

\subsection{DADOS}

O estudo teve como universo os estabelecimentos de laticínios brasileiros registrados no Serviço de Inspeção Federal (SIF) do Ministério da Agricultura, Pecuária e Abastecimento (MAPA). A coleta de dados foi realizada entre novembro de 2014 e janeiro de 2015, por meio de questionário semiestruturado administrado online.

A partir das informações disponíveis sobre os estabelecimentos com registro no SIF no site do MAPA (categoria, razão social e endereço), nós identificamos um total de 1.188 estabelecimentos divididos em cinco categorias (MAPA, 1952): entreposto de laticínios, entreposto usina, fábrica de laticínios, granja leiteira e usina de beneficiamento. Assim, nós utilizamos a amostragem probabilística por estratos, na qual cada categoria foi tratada como um estrato e, dentro de cada categoria, os elementos foram selecionados pelo método de amostragem aleatória simples.

\subsection{ANÁLISE EXPLORATÓRIA}

Após a coleta dos dados, nós realizamos uma análise exploratória, a fim de verificar a existência de respostas em branco e erros de preenchimento. Além disso, nós utilizamos estatísticas descritivas, para avaliar as respostas obtidas e dimensionar a capacidade de extrapolação das conclusões do estudo. 


\subsection{AMOSTRA}

A partir da amostragem inicial, nós conseguimos estabelecer contato efetivo com 377 unidades industriais. Entre os estabelecimentos contatados, 9,8\% (41) não tinham o leite como a sua matéria-prima principal, logo não foram considerados laticínios; 6,7\% (28) recusaram prontamente a participar da pesquisa; e 3,8\% (16) constituíam laticínios inativos. Assim, nós enviamos, efetivamente, 292 questionários às unidades industriais de laticínios (69,5\% dos estabelecimentos sorteados) que aceitaram, num primeiro momento, recebê-los para participar da pesquisa (Figura 1).

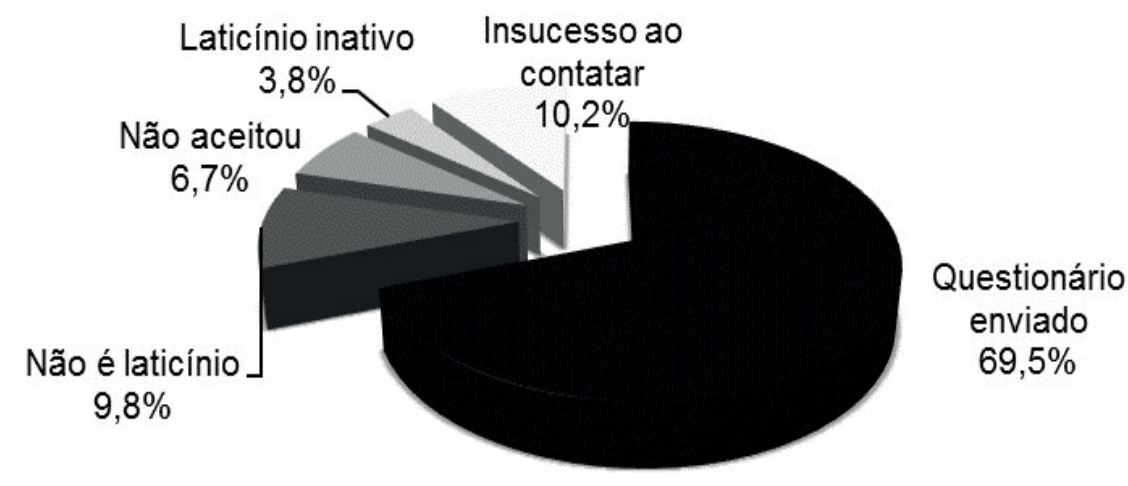

\section{FIGURA 1 - CARACTERIZAÇÃO DA AMOSTRA DE UNIDADES DE LATICÍNIO DA PESQUISA.}

Ao todo, nós obtivemos 68 respostas, equivalente a uma taxa de retorno de 23,3\% em relação ao número de questionários enviados (Figura 2). Desta forma, de acordo com a fórmula genérica de amostragem descrita em Barbetta (2012), considerando-se uma população de 1.188 elementos (MAPA, 2014), tem-se um erro amostral de $\pm 11,8 \%$. Este erro significa que as médias verdadeiras das variáveis estudadas estão entre uma faixa de valores ancorada pela média amostral $\pm 11,8 \%$. 

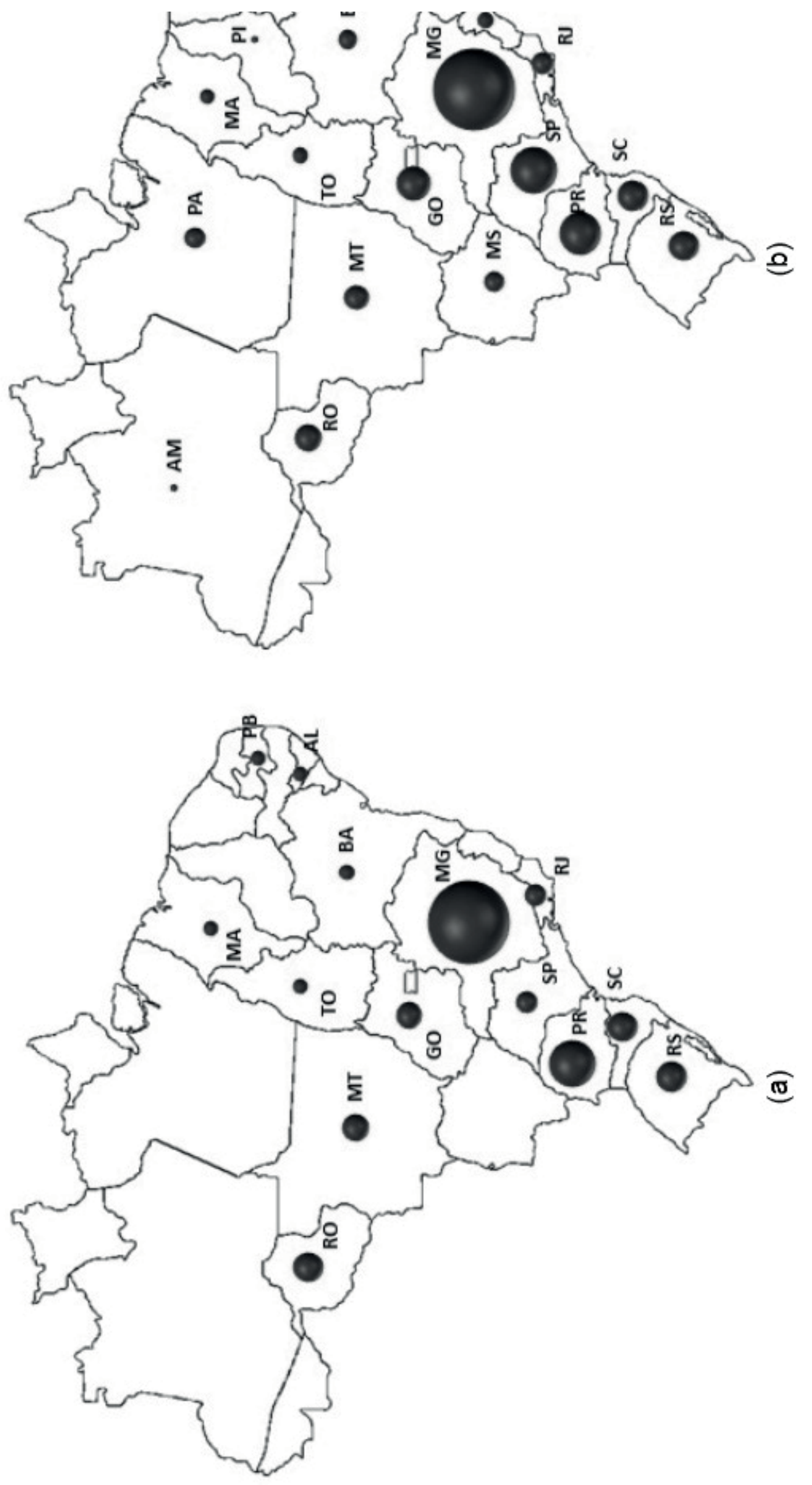

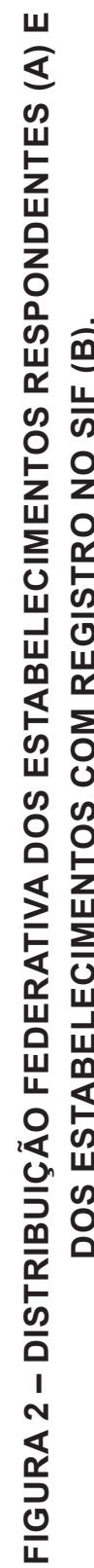




\subsection{ABRANGÊNCIA}

Ao comparar a distribuição territorial da amostra e dos estabelecimentos de laticínios com registro no SIF (Brasil, 2014) por regiões do Brasil, nós identificamos que as respostas obtidas foram provenientes, principalmente, da região Sudeste (Tabela 1). Além disso, houve um baixo número de respostas das regiões Norte, Nordeste e Centro-oeste. Contudo, cabe ressaltar que tal assimetria em relação à distribuição regional dos estabelecimentos participantes segue, de maneira semelhante, a distribuição real dos estabelecimentos entre as regiões brasileiras. Esta associação pode ser comprovada estatisticamente pelo teste do Qui-Quadrado a 5\% de probabilidade ( $p$-valor $=0,604)$.

\section{TABELA 1 - DISTRIBUIÇÃO REGIONAL DOS ESTABELECIMENTOS RESPONDENTES EM FUNÇÃO DO NÚMERO DE UNIDADES DE LATICÍNIO REGISTRADOS NO SIF}

\begin{tabular}{|c|c|c|c|}
\hline Região & $\begin{array}{c}\text { No de estabelecimentos } \\
\text { registrados no SIF* }\end{array}$ & $\begin{array}{c}\text { Respondentes } \\
\text { esperados (\%) }\end{array}$ & $\begin{array}{c}\text { Estabelecimentos } \\
\text { respondentes (\%) }\end{array}$ \\
\hline Centro-oeste & 144 & 12,1 & 8,8 \\
\hline Nordeste & 84 & 7,1 & 5,9 \\
\hline Norte & 91 & 7,7 & 7,4 \\
\hline Sudeste & 638 & 53,7 & 51,5 \\
\hline Sul & 231 & 19,4 & 26,5 \\
\hline
\end{tabular}

Em relação à distribuição estadual dos estabelecimentos respondentes, nós percebemos a ausência de respondentes de alguns Estados que possuem poucos laticínios registrados no SIF, principalmente nas regiões Norte e Nordeste (Figura 2). Contudo, nós consideramos que, devido à taxa de erro amostral assumida $( \pm 11,8 \%)$, à distribuição dos elementos amostrais entre as regiões brasileiras (Tabela 1) e a amostragem aleatória realizada, os resultados obtidos podem ser extrapolados para a população de interesse - estabelecimentos de laticínios com registro no SIF.

\subsection{CARACTERIZAÇÃO DO SETOR}

De acordo com as informações fornecidas pelos representantes dos estabelecimentos de laticínios, pode-se verificar que estes apresentam média de 23,19 anos de operação com um desvio padrão de 18,10 anos. O estabelecimento mais velho da amostra possui 105 anos, enquanto o mais novo, apenas dois.

Quanto à presença de cooperativas e de sociedades de capital no setor, foi identificada uma pequena porção das primeiras em relação ao total de estabelecimentos respondentes (Figura 3). Porém, este percentual é próximo ao de cooperativas com registro no SIF, o que reforça a fidelidade da amostra em relação à população de interesse. Esta associação pode ser comprovada estatisticamente pelo teste do Qui-Quadrado a $5 \%$ de probabilidade ( $p$-valor $=0,574$ ). 


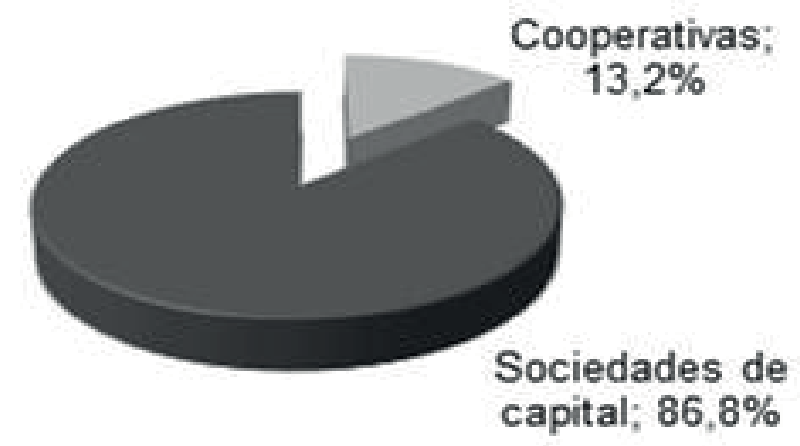

\section{FIGURA 3 - REPRESENTATIVIDADE DO NÚMERO DE ESTABELECIMENTOS RESPONDENTES (A) EM RELAÇÃO AO NÚMERO DE ESTABELECIMENTOS COM REGISTRO NO SIF (B) QUANTO AO TIPO DE SOCIEDADE.}

Sobre o mercado de atuação, nós identificamos que a maior parte dos estabelecimentos pesquisados $(75,0 \%)$ possui atuação em nível nacional, enquanto $10,3 \%$ atuam somente no próprio Estado, 8,8\% somente em outros Estados e, apenas 5,9\% possuem atuação nacional e realizam exportações (Figura 4).

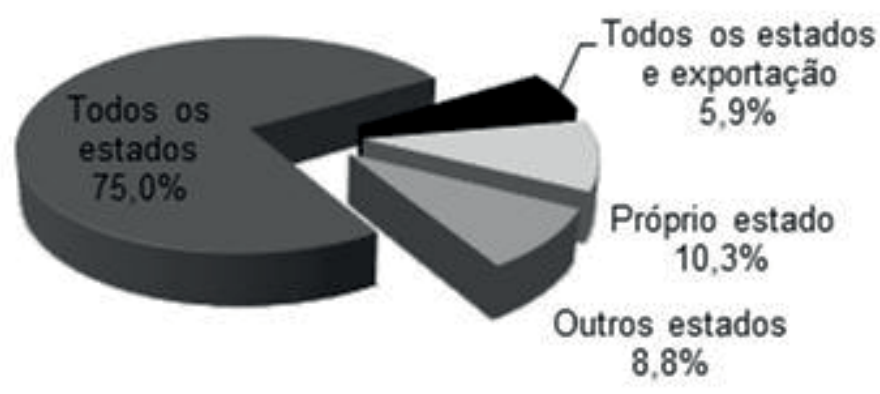

\section{FIGURA 4 - DISTRIBUIÇÃO DOS ESTABELECIMENTOS PESQUISADOS QUANTO AO MERCADO DE ATUAÇÃO.}

Se por um lado o mercado de atuação dos estabelecimentos pesquisados (Figura 4) ilustra a existência de grande porção de laticínios com atuação nacional, ou seja, em todos os Estados, por outro, os dados levam a inferir que apenas uma pequena parcela dos laticínios tem se dedicado a atender nichos de mercados locais e, somente um grupo ainda mais seleto mantém atuação internacional.

Sobre a hipótese de baixo grau de especialização dos estabelecimentos laticínios pesquisados, de acordo com Porter (1998), nós podemos afirmar que muitos destes estariam, assim, perdendo a oportunidade de serem mais competitivos, visto que, para o referido autor, oferecer serviços únicos é uma estratégia que pode tornar uma organização altamente produtiva. Além disso, Dalton et al. (2002) ressaltam que a atuação em mercados locais pode ser mais lucrativa por reduzir os custos de distribuição, principalmente quando aliada ao ganho de escala.

Em relação aos produtos produzidos, nós verificamos que mais da metade (58,8 e 60,3\%, respectivamente) dos laticínios produzem queijos frescos e/ou queijos de média maturação (Figura 5). Estes produtos tem por característica demandar baixo nível de investimento em equipamento, infraestrura e tecnologia (ao contrário do leite UHT, por exemplo) e não necessitar, de maneira considerável, de capital de giro para manter o negócio, como acontece na produção de queijos de longa maturação, em que há a formação de elevados estoques até que os produtos comecem a ser vendidos. Cabe ressaltar que queijos frescos e de média maturação, em geral, podem ser considerados produtos pouco diferenciados, ou seja, de baixa tecnologia. 
Ainda sobre os produtos produzidos, a Figura 5 ilustra que a produção de produtos UHT (bebida láctea, creme e leite) e de produtos secos e desidratados (leite condensado, leite e soro em pó) está concentrada em poucos laticínios. Estes resultados indicam que são poucas as empresas com capital disponível para investir em tecnologias de processamento mais caras como as linhas de produção UHT e sistemas de secagem. Sendo assim, esta constatação não deixa de ser um pouco contraditória quando confrontada com o mercado de atuação, pois estes produtos destacam-se, principalmente, pela vida de prateleira mais longa, o que possibilita sua distribuição em mercados mais longínquos. Desta forma, ao que tudo indica, entre os laticínios que declararam vender seus produtos no próprio Estado e em outros, acredita-se que haja uma pequena porção que tem atuação em nível nacional de maneira efetiva, enquanto o restante, possivelmente, possui apenas uma atuação local e em Estados vizinhos.

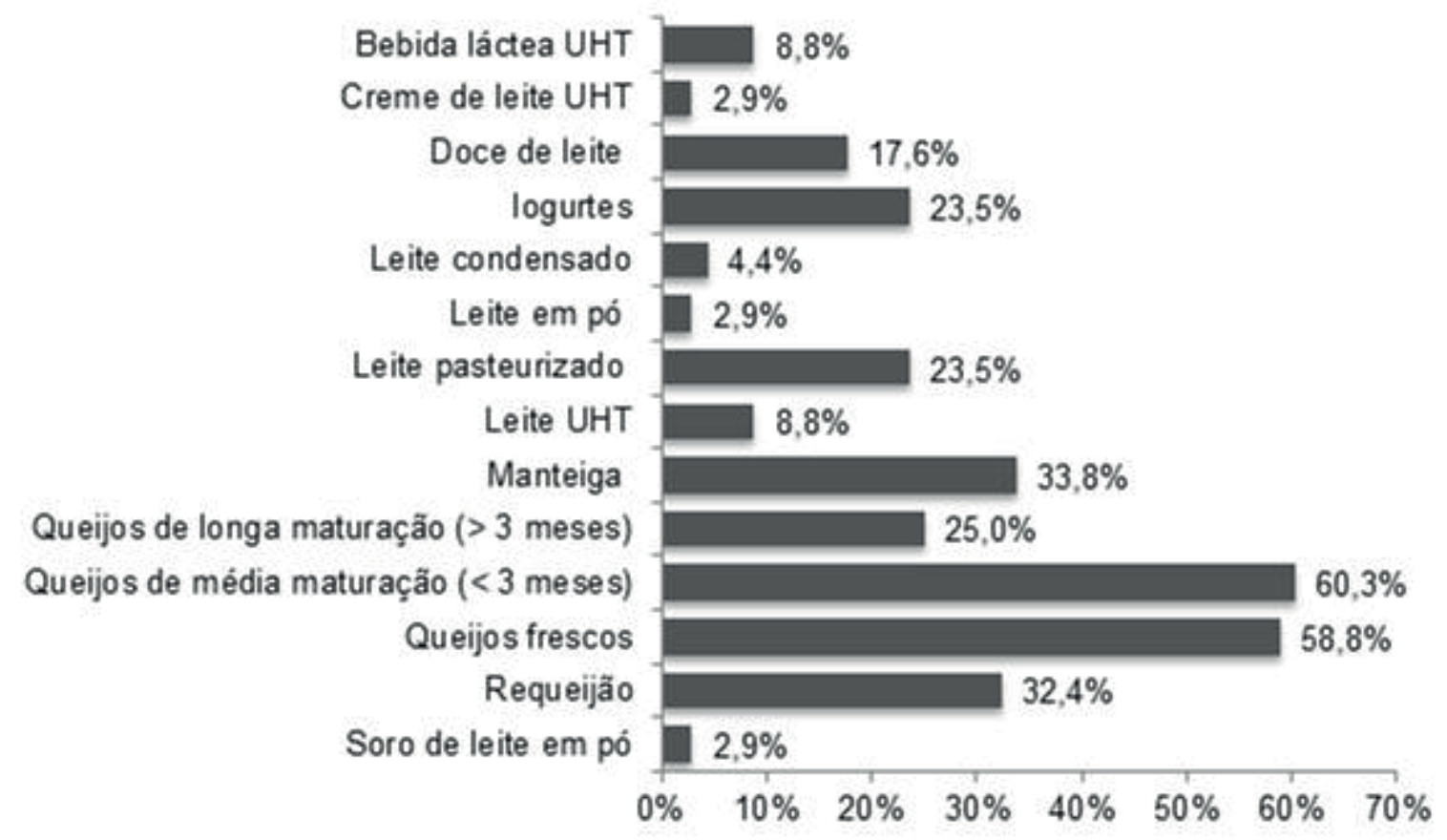

\section{FIGURA 5 - FREQUÊNCIA COM QUE CADA UM DOS PRODUTOS FORAM CITADOS PELOS ESTABELECIMENTOS PESQUISADOS.}

\subsection{CAPACIDADE DE PROCESSAMENTO E OCIOSIDADE}

De acordo com os dados referentes à capacidade instalada, recepção atual e ociosidade dos estabelecimentos pesquisados (Figura 6), nós verificamos que a maior parte dos laticínios possui capacidade de processamento inferior a 112,5 mil litros de leite ao dia, com mediana de 50,0 e média de 113,6 mil litros de leite ao dia. A capacidade de produção total instalada nos estabelecimentos pesquisados é igual a 7,61 milhões de litros de leite ao dia'1. Quando à recepção atual, verificamos que a maior parte dos laticínios possui recepção entre 10,0 e 80,0 mil litros de leite ao dia, com mediana de 31,5 e média de 81,4 mil litros de leite ao dia. A captação total dos estabelecimentos pesquisados é igual a 5,4 milhões de litros de leite ao dia², equivalente a $7,9 \%$ da captação formal do País em 2014 (IBGE, 2016b). Por fim, no que diz respeito à ociosidade, verificamos que a maior parte dos laticínios brasileiros possui capacidade ociosa entre 3,0 e 39,0 mil litros de leite ao dia, com mediana de 10,0 e média de 33,9 mil litros de leite ao dia, respectivamente equivalentes a 20,0 e $29,5 \%$ da capacidade total instalada.

1 Durante a pesquisa, apenas um gestor não informou a capacidade de processamento instalada.

2 Durante a pesquisa, apenas dois gestores não informaram os valores de recepção atual.

3 De acordo com a Pesquisa Trimestral do Leite (IBGE, 2016b), em 2014, foram processados no Brasil 24,7 bilhões de litros de leite. 


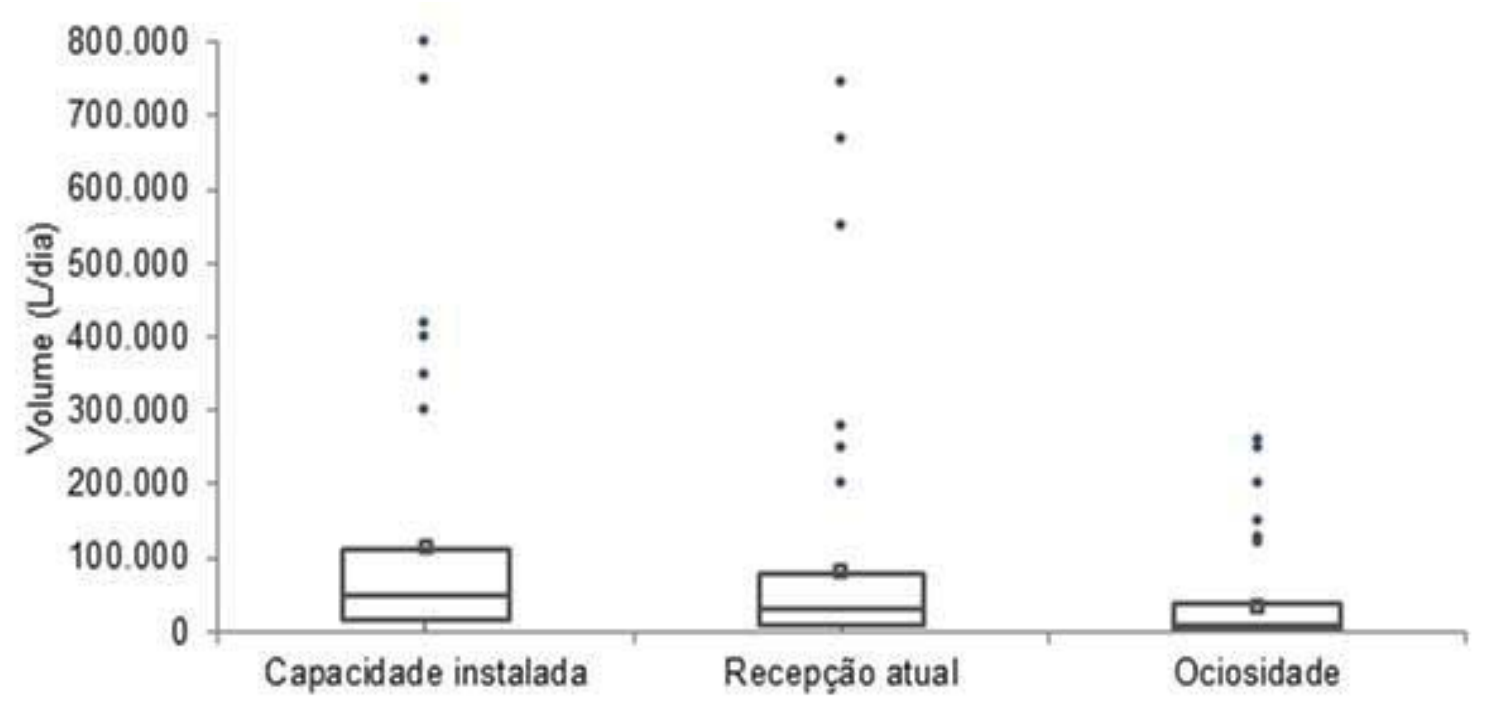

FIGURA 6 - DIAGRAMA BOXPLOT DAS VARIÁVEIS CAPACIDADE INSTALADA, RECEPÇÃO ATUAL E OCIOSIDADE DOS ESTABELECIMENTOS PESQUISADOS.

Considerando o critério de classificação do porte das empresas, de acordo com o número de trabalhadores (Quadro 1), 77,9\% (53) dos estabelecimentos estudados podem ser considerados "Micro" ou "Pequenas empresas" (Figura 7). Estes resultados ilustram a grande heterogeneidade e o elevado número de micro e pequenas empresas existentes no Brasil, corroborando com os cenários já relatados por Ferreira et al. (2008) e Brunozi Júnior et al. (2012).

\section{QUADRO 1 - CRITÉRIO DE CLASSIFICAÇÃO QUANTO AO PORTE DE ACORDO COM O NÚMERO DE EMPREGADOS}

\begin{tabular}{|c|c|}
\hline Classificação & Número de empregados \\
\hline Microempresa & Até 19. \\
\hline Pequena empresa & De 20 a 99. \\
\hline Média empresa & De 100 a 499. \\
\hline Grande empresa & Mais de 500. \\
\hline
\end{tabular}

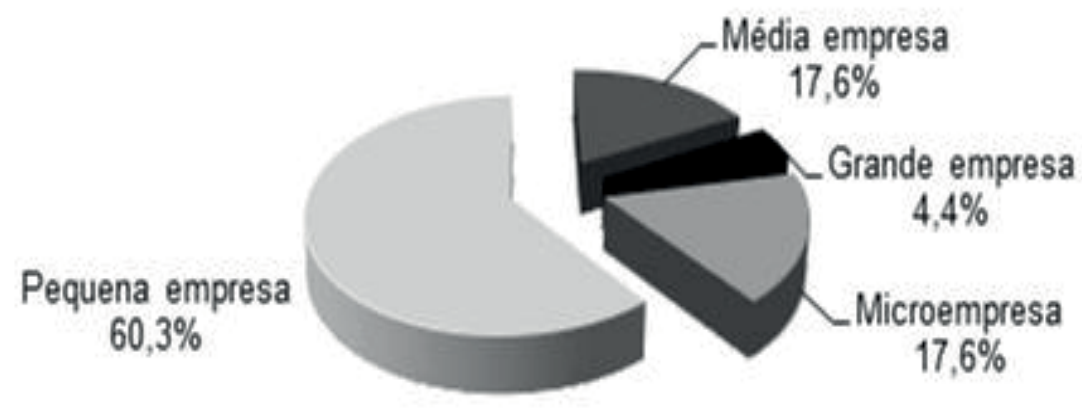


A fim de facilitar a contextualização dos dados apresentados, faz-se necessário caracterizar cada uma destas classes de porte quanto ao número de funcionários e capacidade recepção e de processamento instalada. Assim, pode-se perceber, por exemplo, que os laticínios classificados como microempresas, em geral, recebem menos de 10 mil litros de leite por dia, enquanto os laticínios de médio porte recebem, em média, mais de 100 mil litros de leite por dia (Tabela 2).

\section{TABELA 2 - MÉDIA E DESVIO PADRÃO (ENTRE PARÊNTESES) DO NÚMERO DE FUNCIONÁRIOS, RECEPÇÃO E CAPACIDADE DE PROCESSAMENTO DOS LATICÍNIOS COM REGISTRO NO SIF EM FUNÇÃO DE SEU PORTE}

\begin{tabular}{|c|c|c|c|c|}
\hline Parâmetro & Microempresa & $\begin{array}{c}\text { Pequena } \\
\text { empresa }\end{array}$ & Média empresa & Grande empresa \\
\hline Número de funcionários & $11,00(4,65)$ & $44,02(19,07)$ & $181,75(100,58)$ & $970,00(268,51)$ \\
Recepção (L/dia) & $7.755(8.783)$ & $47.605(56.503)$ & $117.917(69.039)$ & $655.000(98.362)$ \\
$\begin{array}{c}\text { Capacidade de } \\
\text { processamento (L/dia) }\end{array}$ & $11.736(10.599)$ & $74.610(85.642)$ & $172.917(117.366)$ & $783.333(28.867)$ \\
\hline
\end{tabular}

Para analisar os estabelecimentos quanto ao percentual de capacidade ociosa, foram consideradas três categorias de ociosidade: baixa (menor que 25\%), média (entre 25 e $50 \%$ ) e alta (maior que 50\%). Assim, nós verificamos que, proporcionalmente, os índices mais altos de ociosidade estão concentrados entre os estabelecimentos de laticínios de micro e pequeno porte, enquanto os mais baixos estão concentrados entre os estabelecimentos de médio e grande porte (Figura 8).

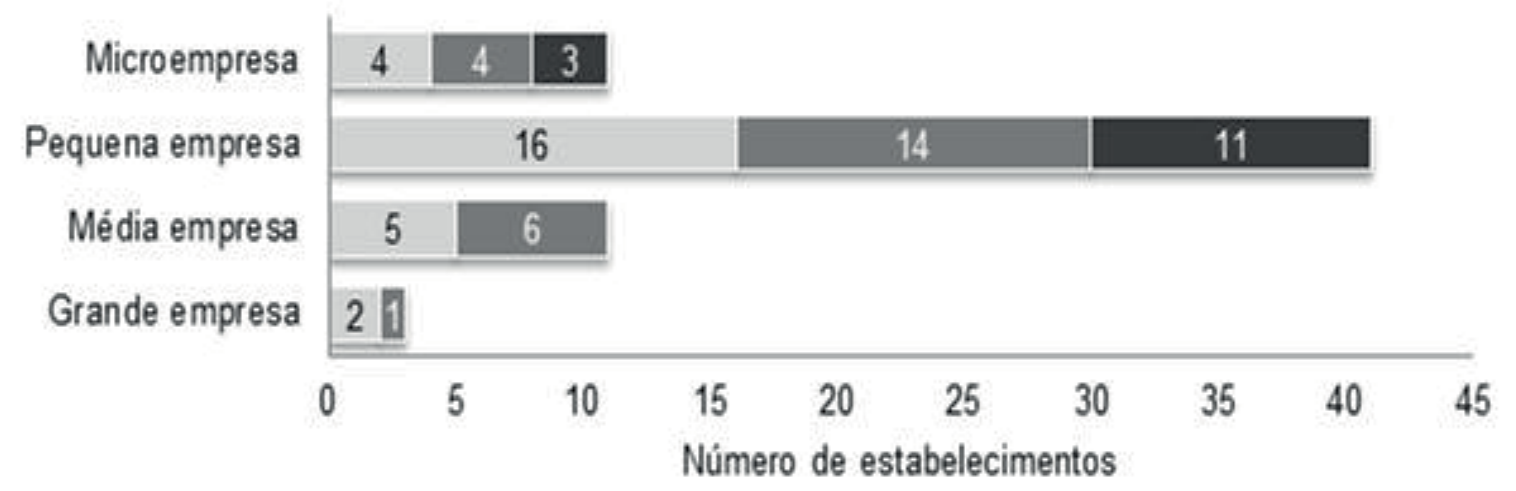

\section{Baixa $=$ Média $=$ Alta}

\section{FIGURA 8 - RELAÇÃO DO NÚMERO DE ESTABELECIMENTOS CONTIDOS EM CADA UM DOS NÍVEIS DE OCIOSIDADE EM FUNÇÃO DO PORTE.}

Cabe ressaltar que a capacidade ociosa leva em consideração a capacidade produtiva considerando-se a operação em três turnos. Desta forma, pode ser que, em parte, os altos níveis de ociosidade verificados entre os estabelecimentos de laticínios de micro e pequeno porte sejam devido ao fato de que muitos destes laticínios possuem operação restrita a apenas um ou dois turnos. Além disso, nós acreditamos que estes laticínios enfrentam maiores dificuldades para controlar o preenchimento da capacidade produtiva, o que pode ser atribuído ao fato de que os fornecedores tornam-se mais representativos à medida que o porte do laticínio diminui. 
De qualquer forma, a presença de altos níveis de ociosidade entre alguns estabelecimentos de laticínios de micro e pequeno porte pode ser associada à baixa competitividade destes estabelecimentos. Tal fato pode ser evidenciado pela dificuldade destes laticínios operarem com pelo menos $50 \%$ de suas respectivas capacidades. Assim, este cenário pode ser um dos principais fatores capazes de desencadear operações de fusão e aquisição, alimentando o fenômeno da concentração da produção no setor de lácteo do Brasil. Ou, por outro lado, ao invés de causa, este cenário também pode ser visto como efeito. Se estes laticínios, com altos níveis de ociosidade, possuem menor desempenho e, portanto, são menos competitivos, também se pode inferir que estes estariam aos poucos sendo excluídos do mercado e, por isso, operando tão abaixo de suas capacidades.

\subsection{PERFIL DOS GESTORES}

De acordo com os dados referentes ao tempo de experiência dos gestores no setor, na função e no cargo atual (Figura 9), nós verificamos que a maior parte dos gestores ocupa o cargo atual há pelo menos 3,00 anos, com mediana de 6,00 e média de 8,48 anos ${ }^{4}$. Quando ao tempo de experiência na função, nós verificamos que a maior parte dos gestores possui entre 6,00 e 18,00 anos, com mediana de 11,00 e média de 13,22 anos. Por fim, no que diz ao tempo de experiência no setor, nós verificamos que a maior parte dos gestores possui entre 8,00 e 22,50 anos, com mediana de 15,00 e média de 15,75 anos. Assim, com estes resultados podem suscitar a hipótese de que entre os laticínios brasileiros há uma preferência generalizada por gestores que, a princípio, tenham experiência prévia na função e no setor.

A hipótese levantada de acordo com a análise da Figura 9 pode ser comprovada por meio do teste $t$ de Student para amostras emparelhadas a $5 \%$ de probabilidade, no qual se verificou que a média do tempo em que o atual gerente ocupa o cargo é, respectivamente, inferior às médias do tempo em que $o$ atual gerente tem de experiência no setor ( $p$-valor $<0,001)$ e na função ( $p$-valor $<0,001$ ). Com o mesmo teste, nós também identificamos que, em média, os gerentes possuem mais tempo de experiência no setor do que na função ( $p$-valor $=0,001)$. Estes resultados suscitam a hipótese de que, no processo de escolha dos gerentes, a experiência prévia no setor pode ser uma variável mais importante do que a experiência prévia na função, ou seja, em geral, os gestores escolhidos são pessoas do próprio setor.

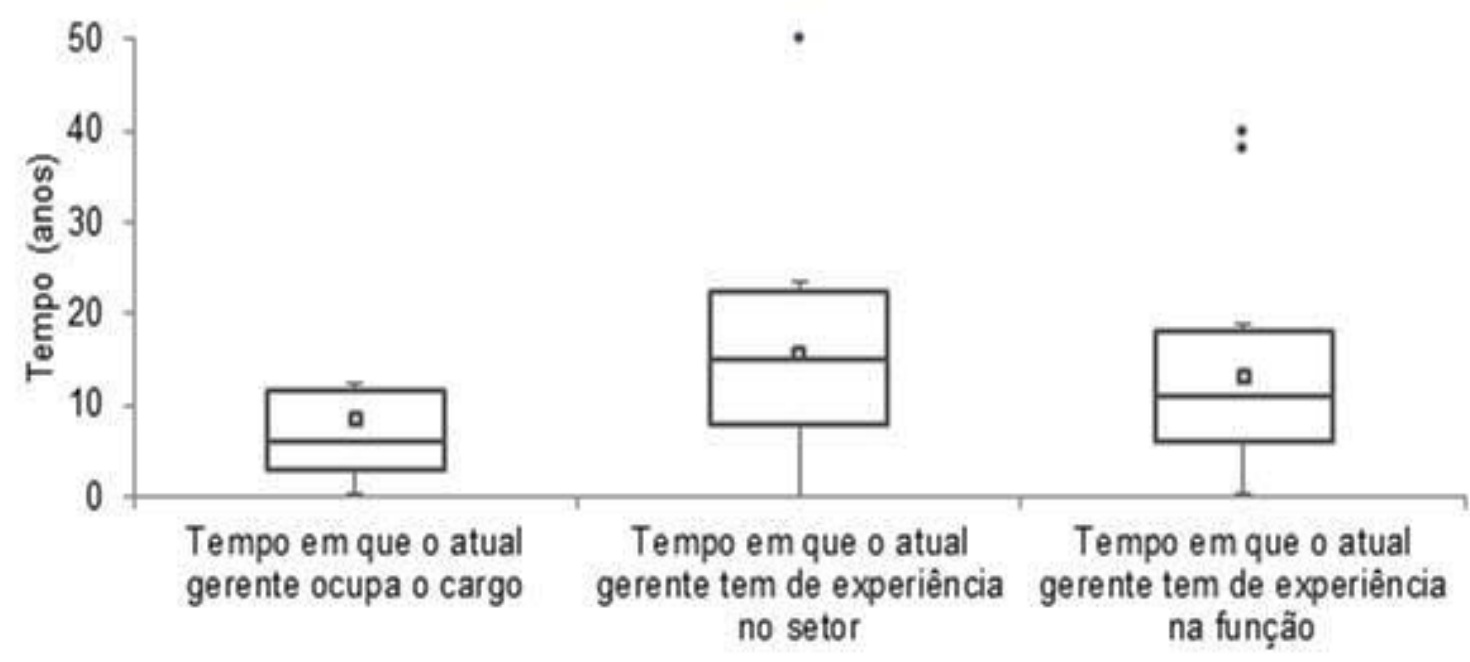

\section{FIGURA 9 - DIAGRAMA BOXPLOT DAS VARIÁVEIS DE TEMPO DE EXPERIÊNCIA DO GERENTE NO SETOR, NA FUNÇÃO E NO CARGO ATUAL.}

$4 \quad$ Durante a pesquisa, apenas um gestor não informou o tempo em que o atual gerente ocupa o cargo, além do tempo em que este tem de experiência na função e no setor. 


\subsection{PRINCIPAIS DIFICULDADES APONTADAS PELOS GESTORES}

Em relação aos possíveis fatores de ineficiência apontados pelos gestores, destacamse as altas frequências associadas a fatores relacionados ao mercado de laticínios (concorrência desleal e oscilações do mercado) e à mão de obra (falta de mão de obra qualificada). Contudo, cabe ressaltar que a falta de mão de obra em geral e o custo elevado da mão de obra não figuraram entre os fatores mais citados (Figura 10).

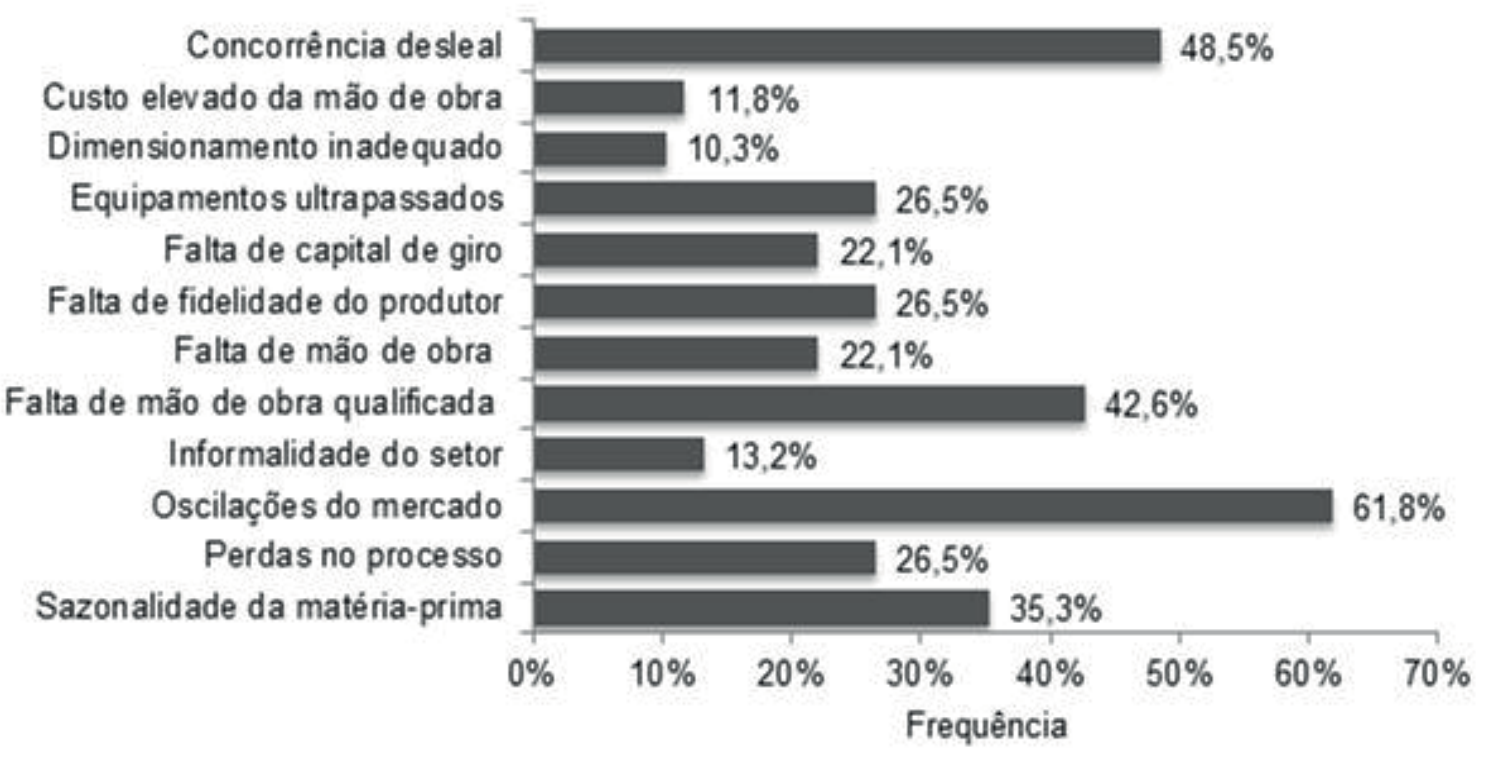

\section{FIGURA 10 - FREQUÊNCIA COM QUE OS FATORES DE INEFICIÊNCIA APONTADOS PELOS GESTORES.}

\section{CONCLUSÃO}

Aindústria de laticínios brasileira é composta, basicamente, por micro e pequenas empresas, com capacidade de processamento inferior a $100 \mathrm{mil}$ litros/dia. Estes estabelecimentos, em geral, são sociedades de capital $(86,8 \%)$, que produzem produtos com pouco diferencial tecnológico. Este retrato do setor lácteo nacional indica que, em geral, a maioria dos laticínios não apresenta diferenciação.

Por fim, também se pode concluir que os gestores contratados pelos laticínios têm, em sua maioria, pelo menos 6,00 anos de experiência prévia na função e 8,00 no setor. Ademais, em geral, estes são formados no próprio setor.

\section{ABSTRACT}

\section{THE DAIRY INDUSTRY IN BRAZIL - AN EXPLORATORY STUDY}

The dairy industry is of great importance to Brazil due the supply products of high nutritional value and the generation of employment and income. So, this study aimed to characterize Brazil's dairy establishments, with registration in Serviço de Inspeção Federal (in Portuguese) (SIF), as the productive aspects, management and marketing. A population composed of 1,188 dairy with SIF we contacted 377 diaries and sent surveys to 292 managers of dairy establishments between November 2014 and January 2015, resulting in a total of 68 responses. From the responses data, an exploratory analysis was performed by calculating descriptive statistics of variables collected to characterize the 
sample in question, proceeding with average test and association test when necessary. We consider the sample representative of the population of dairy establishments with regard to the geographical distribution among Brazilian regions. The establishments' respondents were, basically, micro and small enterprises with low power of processing. The idleness is a problem with greater presence in the micro and small establishments, the result of reduced operation in one or two shifts, and difficulties of milk acquisition. These establishments are dedicated to the service of markets at the regional and national level, with mostly fresh cheeses and average maturity. The managers have prior experience both in function and in the dairy industry, being the latter, apparently, more valued by companies. The main difficulties identified by managers are related to unfair competition, market fluctuations and lack of skilled labor.

KEYWORDS: SIZE, DAIRY PRODUCTS; MILK; FOODS; PLANT.

\section{REFERÊNCIAS}

1 ABIA. Associação Brasileira das Indústrias da Alimentação. Indústria da alimentação - principais indicadores econômicos. Disponível em: <http://www.abia.org.br/vst/faturamento.pdf>. Acesso em: 22 jan. 2016.

2 BARBETTA, P.A. Estatística: Aplicada às Ciências Sociais. 8.ed. Florianópolis: UFSC, 2012. 318p.

3 BRUNOZI JÚNIOR, A.C.; ABRANTES, L.A.; FERREIRA, M.A.M.; GOMES, A.P. Mercado e Tributação: Uma Abordagem Teórica sob a Perspectiva de Estruturas de Mercado na Cadeia Agroindustrial do Leite. Revista Econômica do Nordeste, v.43, n.1, p.93-108, 2012.

4 DALTON, T.J.; CRINER, G.K.; HALLORAN, J. Fluid Milk Processing Costs: Current State and Comparisons. Journal of Dairy Science, v.85, n.4, p.984-991, 2002.

5 FAO. Organização das Nações Unidas para Agricultura e Alimentação. Produção da Agropecuária. Disponível em: <http://faostat3.fao.org/faostat-gateway/go/to/home/E>. Acesso em: 22 jan. 2016.

6 FERREIRA, M.A.M.; ABRANTES, L.A.; PEREZ, R. Investigação de grupos estratégicos na indústria de laticínios por meio da abordagem multivariada. Revista de Administração Mackenzie, v.9, n.2, p.152-172, 2008.

7 IBGE. Instituto Brasileiro de Geografia e Estatística. Pesquisa Pecuária Municipal. Disponível em: <http://www.sidra. ibge.gov.br/bda/tabela/listabl.asp?c=74\&z=t\&o=24>. Acesso em: 22 jan. $2016 a$.

8 IBGE. Instituto Brasileiro de Geografia e Estatística. Pesquisa Trimestral do Leite. Disponível em: <http://www.sidra. ibge.gov.br/bda/tabela/listabl.asp?c=1086\&z=t\&o=24>. Acesso em: 22 jan. $2016 \mathrm{~b}$.

9 MAPA. Ministério da Agricultura, Pecuária e Abastecimento. Regulamento da Inspeção Industrial e Sanitária de Produtos de Origem Animal (RIISPOA). 1952. 154p. Disponível em: <http://www.agricultura.gov.br/animal/mercadointerno/requisitos-sanitarios>. Acesso em: 22 jan. 2016.

10 MAPA. Ministério da Agricultura, Pecuária e Abastecimento. Relatório de Estabelecimentos. Disponível em: <http:// sigsif.agricultura.gov.br/sigsif_cons/!ap_estabelec_nacional_rep>. Acesso em: 15 set. 2014.

11 MAPA. Ministério da Agricultura, Pecuária e Abastecimento. Valor Bruto da Produção. Disponível em: <http://www. agricultura.gov.br/ministerio/gestao-estrategica/valor-bruto-da-producao>. Acesso em: 22 jan. 2016.

12 MILKPOINT. Ranking Leite Brasil: captação das maiores empresas cresce 5,9\% em 2014. Disponível em: <http:// www.milkpoint.com.br/cadeia-do-leite/giro-lacteo/ranking-leite-brasil-captacao-das-maiores-empresas-cresce-59-em2014-94625n.aspx>. Acesso em: 01 mai. 2015.

13 MTE. Ministério do Trabalho e Emprego. Relação Anual de Informações Sociais - RAIS. Brasília: RAIS. Disponível em: <http://bi.mte.gov.br/>. Acesso em: 24 jun. 2015.

PORTER, M.E. Clusters and the new economics of competition. Harvard Business Review, v.77, n.6, p.77-90, 1998.

15 SEBRAE. Serviço Brasileiro de Apoio às Micro e Pequenas Empresas. Estudo Comparativo: pequenas empresas (MPEs) versus grandes empresas (MGEs) no Estado de São Paulo. Pesquisas Econômicas. São Paulo, 1998. 58p. 


\section{AGRADECIMENTOS}

Nós agradecemos ao Conselho Nacional de Desenvolvimento Científico e Tecnológico CNPq pelo apoio financeiro (bolsa de mestrado do primeiro autor). 